JOSÉ RAMÓN BENITO

\title{
Universidad y filosofía *
}

T A manera en que yo los invito a que abordemos el tema, Lque por fortuna nos deja con bastante amplitud para hacerlo y discurrir en torno a él, es la siguiente: preguntándonos, ¿cuáles son las relaciones entre ambas realidades humanas: universidad por una parte y filosofía por la otra? ¿Qué es lo que une a estas realidades? (si es que hay alguna unión entre ellas).

El tema ha sido presentado en este ciclo dentro del campo de la educación, y desde luego que está en este ámbito, pero podría yo decir tratando de cerrar un poco la amplitud del mismo que en parte está dentro y en parte está fuera de lo que es la educación. ¿Qué quiere decir eso? Eso quiere decir que ni la universidad como institución, ni la filosofía como un conocimiento, agotan el campo de la educación; se inscriben en él ciertamente, pero por una parte repito no lo agotan y en otro sentido tienen algo más; a mbas tienen otras dimensiones que la estricta o puramente educativa.

Así pues, los puntos con los que trataremos de hilvanar el desarrollo son, primero, poner frente a frente estos dos conceptos: universidad y filosofía. En segundo lugar, tratand o de ver después de esta confrontación, esta revisión o análisis de uno y otro de estos significados; qué es lo que une a una cosa con la otra, cuál es la conectiva, de qué:grado, de qué densidades, cuál es el alcance, la fuerza q̉ue le podemos dar a esta conjunción en

* Texto de la conferencia dictada en el 1TAM el 12 de abril de 1984, durante el ciclo "Presencia del hombre en la reflexión filosófica". 
su función copulativa. Y en tercer lugar las perspectivas que nosotros podemos encontrar de esta revisión.

Entremos por tanto en el primer punto, el de ver qué encontramos en el significado de universidad. Quisiera anticipar una cierta subdivisión en su desarrollo. Por un lado consideraré ciertos hechos, ciertas ideas y trataré con ello de identificar, de ver qué es la universidad, haciendo unas cuantas referencias de tipo histórico, no porque piense ( $\mathrm{y}$ menos en un asunto como éste), que sea poco necesario o de alguna manera prescindible el hacer la consideración de su historia, sino por los límites de esta charla y, como lo apuntaré también, por las variaciones y la diversidad de formas en que la universidad se ha presentado a lo largo de la historia. Me parece que hemos de encontrar algo que pueda ser más permanente, más constante. Para ello procuraré más bien examinar algunas ideas de lo que se ha expresado y de lo que se ha pensado acerca de la universidad, y algunos hechos en torno a esto.

En segundo lugar, en este primer punto, después de esta consideración de hechos e ideas, pretendo que revisemos la problemática que encontramos en el análisis de estos hechos y de estas ideas. Así pues, iniciemos el primer punto.

El distinguido historiador de la filosofía medieval Etienne Gilson, en un opúsculo intitulado "Sabiduría y amor", resume muy bien el hecho de la universidad como la tenemos ante nuestros ojos en la actualidad:

Hoy por hoy el conocimiento se vende en grandes tiendas por departamentos, llamadas colegios universitarios o universidades, donde los estudiantes pueden comprar según lo anunciado el tipo de conocimiento que se acomoda a su gusto o satisface sus necesidades. ${ }^{1}$

y advierte el autor que el gusto de los "clientes" no es necesariamente verdadera preferencia, ni mucho menos un entusiasmo, una pasión; a veces simplemente es el mal menor, un poco en la línea de la aritmética de los placeres de Epicuro: "acepta el dolor

' Etienne, Gilson, "Sabiduría y amor", en El amor a la sabiduria, AYSE, Caracas 1979, p. 48. 
que puede traerte un placer mayor o evitarte un dolor mayor". En este sentido, la selección del estudiante puede ser muchas veces la huída de otras zonas más riesgosas, más amenazantes, ya sea por sus exigencias académicas o por no ser lucrativas, entre algunos casos que pueden presentarse.

Se trata aquí de esa línea de hechos en que aparece la universidad dentro de la perspectiva de la sociedad de consumo. Ciertamente en 1951, fecha del escrito de Gilson, no había o por lo menos no habían adquirido la difusión y la generalización que tienen en estas épocas las tiendas de autoservicio. Pero estas grandes tiendas de departamentos que son las universidades están alcanzando ahora esta nueva dimensión de tiendas de autoservicio... Las nuevas técnicas didácticas ya lo anticipan; sistemas de televisión, enseñanza programada, diferentes formas y sistemas en donde la intervención de los dependientes del conocimiento puede ser reducida al mínimo.

La educación, que primordialmente consiste ante todo en la relación de personalidades, en el diálogo de personas "en madurez desigual", como dice Gusdorf, pierde sus condiciones de posibilidad en esta nueva perspectiva. Esa comunicación personal, participada en común con una aspiración y con una búsqueda conjunta, era inicialmente lo fundamental en las universidades. En cambio, estos modernos sistemas de distribución de los conocimientos perfectamente preparados, empaquetados y acomodados para el consumo, esa universidad, ese sistema educativo por paquetes, crea una situación en donde el sujeto que participa como estudiante se limita simplemente a escoger y seleccionar una mercancía de acuerdo a ciertos propósitos, que en gran medida ni siquiera tienen su origen en él mismo ni responden al genuino sentido de la actividad cognoscitiva. En todo caso, su elección se debe a preferencias y exigencias ajenas por completo al ser genuino de la universidad y de los sujetos que la constituyen.

Creo que la preocupación por la comercialización del saber y sobre todo por su automatización, tal como está siendo captada en esta apreciación de los hechos que nos muestran como aparece hoy la universidad, no es simplemente una preocupación que podría explicarse como una defensa gremial de tinte ideológico, asignada en las demandas de los dependien- 
tes que como clase se sienten desplazados. Creo que es algo más hondo, creo que en realidad lo que está en juego es el ser de nuestra cultura y el ser del hombre. Quizás lo último, el ser del hombre, tenga que matizarse y espero que en el desarrollo lo podamos ir logrando y pueda tener un enunciado más justo, más proporcionado, en la parte final de esta conversación.

De cualquier manera creo que el problema de si los profesores realmente hacen algo o no ha sido puesto a discusión de muchas maneras y en muchos lugares; quizás uno de los más fuertes sea en esta obrita de san Agustín, el De Magistro, en el que la conclusión pudiera ser que nadie enseña nada a nadie, $\mathrm{y}$ modernamente parece sugerirlo el título de una obra de Gusdorf, de quién hacía una referencia anteriormente: ¿para quélos profesores? ${ }^{2}$

¿Qué se quisiera entonces de la universidad? Podríamos decir más concretamente: ¿qué tiene que ser, o qué tendría, qué habría de ser la universidad? Trataremos de contestar a ello viendo qué proyectos, qué intenciones hacen posible esta relación personal de quienes integran y constituyen esa comunidad. ¿Qué se quisiera de la universidad? Para responder, podríamos oir las palabras de Whitehead, quien nos dice que

los estudios universitarios son el gran período de generalización. El espíritu de generalización debería dominar la universidad; en ella el estudiante debería partir de las ideas generales y estudiar sus aplicaciones a las cosas concretas. 3

Como que esto trae muy claro el eco de aquello que Jaeger expresa como el espíritu de la paideia griega, su sello distintivo, "la generalidad teórica de método intelectual aplicable a cualquier problema". Este relacionar lo general con lo particular, pero teniendo siempre presente el sentido, la dirección, el espíritu o principio arquitectónico, esto que está de alguna manera haciendo falta hoy, como veremos más claramente en

Zeorges Gusdorf, ¿Para qué los profesores? EDICUSA, Madrid 1969

3. Alfred North Whitehead, Los fines de la educación. Paidós, Buenos Aires 1961, p. 41.

4. Werner Jaeger, Cristianismo primitioo y paideia griega, FCE, Méxíco

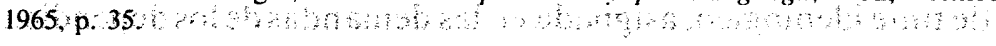


los pasos siguientes, y que sólo su recuperación y su adecuado logro pueden dar vida verdadera a lo que se llama universidad. J.H. Newman, este otro autor inglés que ha escrito una obra que es clásica en cuanto al significado de la universidad, dice que es

un lugar donde se enseña el conocimiento universal. Cualquiera que sea la razón original, por lo demás desconocida, por la que haya sido adoptado, yo no hago sino recordar el sentido reconocido, el sentido popular del término, cuando digo que una universidad debería enseñar el conocimiento universal. ${ }^{5}$

Esta es su tarea y su misión específica. Ahora bien, todavía tenemos nosotros que situarnos con un poco más de precisión en lo que debemos entender por esta generalización o universalidad. Podría en un principio pensarse simplemente que es de orden acumulativo, cuantitativo, que es preciso que estén representados los distintos saberes y que de alguna manera los distintos dominios del conocimiento queden incluidos dentro de la actividad universitaria. Pero, ciertamente, en esas condiciones seguiríamos en la mera situación de un conjunto de acomodos, de paquetería de distribución, de clasificación de los conocimientos sin más sentido. Sobre esta posible interpretación Maritain recalca la importancia de la jerarquía interna y cualitativa en este conjunto de conocimientos. ${ }^{6}$

Hemos partido de la consideración de cómo se presenta la universidad ahora, hemos escuchado algunas ideas acerca de cómo habría de ser. Nos hemos aproximado con esto al ser de la universidad, ante todo tendríamos que precisar toda vía que no existe la universidad, existen universidades y que esto significa que la universidad la tenemos que considerar siempre como una realidad histórico-cultural, en medio de condiciones, de características que son diversas y cambiantes y que en la vida las sociedades van moldeando e influyendo, marcando ciertas pautas, ciertos horizontes a lo que es la actividad de la universidad. Estas vicisitudes en su desarrollo, en su historia, en su vida,

5 Apud Jacques Maritain, La educación en este momento crucial, Desclée de Brouwer, Buenos Aires 1954, p. 96.

6 lbid. 
esta relación histórico-cultural de la universidad es algo suyo desde que apareció con ese nombre y con las características que estamos tratando de situar y definir en esta charla, características que van unidas a esta forma de organización y de actividad humana desde sus orígenes en la edad media. Un periodo que podríamos llamar casi el último, dentro de esta forma de darse es aquél en que la universidad todavía mantiene algo de la vida propia de sus orígenes en los siglos XVI y XVIII y por fin, en un resurgimiento, pero con una orientación de características nuevas, en la Alemania del siglo XIX y algo similar encontramos en los países latinos, principalmente en Francia, en Italia y en parte de España.

Es importante advertir que desde sus orígenes la universidad medieval estuvo relacionada, aunque a veces se nos suele presentar la cosa de otra manera, con la preparación profesional, lo cual quiere decir que estaba en relación con las necesidades y los tipos de actividad que correspondían a la sociedad de entonces y que requerían una determinada preparación; por lo tanto era lo que la sociedad demandaba. Básicamente, esto dio lugar a la constitución de estas universidades, nos dice García Morente en su estudio sobre la universidad: las grandes facultades mayores eran la facultad de teología, la facultad de medicina y la de derecho, cada una de las cuales respondía a la preparación que se requería para funciones específicas dentro de la sociedad occidental cristiana de la edad media. Y la facultad menor, facultad de artes, estaba al servicio de la preparación anterior y era un poco lo que después han venido a cubrir los centros de educación media, los colegios o instituciones de formación preparatoria. En esta facultad de artes la universidad reunía al mismo tiempo los diferentes saberes que tenían un carácter más independiente, en cuanto que no respondían de manera directa a las actividades que la sociedad demandara. ${ }^{7}$

Por tanto, podemos ver que la universidad ha tenido desde sus orígenes esta dirección $u$ orientación, o al menos una relación con lo que la sociedad requiere. Lo cual todavía no nos permitiría encontrar algo que nos dé un fundamento más

7 Cfr. Manuel García Morente, Escrilos Pedagógicos, Espasa-Calpe, Madrid 1975, p. 30. 
sólido, más definitivo para defender y proponer que la universidad tenga ésta como relación fundamental, vital a la cultura y a la vida humana que planteábamos anteriormente, sino que más bien parece dejarnos en una relación de producto para el consumo.

Ciertamente, la relación de maestros y alumnos que encontramos en el origen de las universidades, por la actividad que promueve, por las condiciones y por las necesidades de la vida a que responde, así como por el hecho de que surge del interés de personas que se encuentran dedicadas a diferentes campos del conocimiento, o que tienen interés de recibir la preparación correspondiente en estos campos y para estas funciones que la sociedad requiere, nos manifiesta una relación eminentemente personal y social a la vez.

Al mismo tiempo encontramos que para aprovechar mejor su posibilidad de comunicación y de relación, maestros y alumnos se reúnen y forman precisamente esto que venía ya preparándose en las escuelas medievales y que yo considero como el futuro maduro de la sociedad y de la cultura medieval: las primeras universidades en Occidente.

Pero como es claro, la relación de maestros y alumnos ha existido desde el momento en que los hombres en su vida, en su vida propiamente humana y en sus diferentes formas de convivencia, han buscado la comunicación del conocimiento y han buscado el saber, han buscado la verdad. En este sentido es algo que es permanente en las sociedades humanas, que tiene una función o una figura que se da desde las sociedades más primitivas o elementales como comunicación de lo que es indispensable de ciertas tradiciones, de ciertos elementos que son el fundamento activo del grupo, de las posibilidades de desarrollo de vida del grupo como tal y de las personas que lo forman, hasta llegar a formas de relación cultural e intelectual más complejas.

Esta reunión de profesores y de estudiantes que buscan organizadamente el saber, y por qué no decirlo directamente, la verdad, es una reunión que busca o en la que sus integrantes buscan organizadamente el saber en la medida en que este saber está estructurado, tiene una unidad y una jerarquía. No se trata simplemente de la organización funcional para que la comuni- 
dad desempeñe cierta actividad y los integrantes de la misma reconozcan cada quien sư papel, sino de una organización, de un orden en cuanto sentido de su actividad, el para qué de la misma. Y con esto vemos ya claramente que el servicio a la sociedad, que la universidad per se tiene que dar y desde sus orígenes ha venido dando, no tiene que ser en términos de sujeción o sumisión.

Este servicio a la comunidad que la universidad viene a cumplir y a la vezsu independencia es lo que Cristopher Dawson nos expresa diciendo que "es el lugar de estudio libre que debe propiciar en los estudiantes un sentido común" (en el doble sentido que puede tener esta expresión, pero aquí sobre todo subrayado lo común en cuanto comunitario), "de los valores intelectuales y de su proyección social". 8

En esta búsqueda organizada del saber, maestros y estudiantes, los estudiosos de la universidad, tratan de ver las dos actividades fundamentales que en la actualidad se reconocen como pertenecientes a ella: investigación y docencia.

La importancia de la investigación para la vida intelectual, para el saber y para la función docente es algo que no se puede discutir. Sin embargo, también es cierto que en la forma en que se compone este organismo, esta comunidad de que hablamos, la relación es preferente y primordialmente de carácter docente. De ahí entonces tenemos que considerar las relaciones entre estas dos modalidades de la vida intelectual tal como ésta se desarrolla en lo que conocemos cono universidad, advirtiendo desde luego que se trata de relaciones un tanto complejas. Es claro con todo que estas dos actividades se corresponden por el ser mismo de la universidad, tal como ésta se define, por cómo surgió y por los componentes de la misma.

Sí, esta comunidad de profesores y estudiantes que buscan organizadamente el saber, la universidad, podemos decir que es como un lugar, es donde se da esta búsqueda y el resultado mismo que de ella se obtiene. La universidad es, por lo tanto, relación o comunidad de profesores y estudiantes, un lugar de conocimiento, es el lugar que socialmente se le hace al conoci-

8 Apud Carlos De la Isla, "Reflexiones en plural sobre un camino hacia" lo humano en la educación superior", en Revista del ITAM (México), 1973, núm. 1, p.6. 
miento. Pero en la medida en que el conocimiento se limite únicamente a ser repetido y acumulado en esta comunidad, en este lugar social del conocimiento, el conocimiento va a convertirse en algo que práctica mente, cada vez más, se volverá ajenoy hasta hostil a la vida. El conocimiento, como parte del hombre y de su actividad intelectual, como la manifestación más propia de este orden de la inteligencia, necesita un desarrollo, un progreso en donde la apropiación de la verdad tiene que irse manteniendo en forma viva, de manera que estésiempre abierto en un sentido dinámico, en un sentido de crecimiento y de renovación, de revisión permanente.

Ciertamente, yo admito que podemos hablar de la verdad con un sentido objetivo, yo no pienso que la verdad quede simplemente al nivel de mi parecer y de lo que podría llamarse un sentido casi de expresión burguesa de la verdad, como algo de propiedad privada, "mi verdad". Yo creo que puede haber una verdad propia, un sentido propio de la verdad, pero yo creo que para que la verdad sea verdad para mí, la tengo que hacer mía. Y este hacer mía la verdad requiere que la verdad sea verdad para todos, verdad en sí, y también requiere este proceso de apropiación en el sentido antiguo de conocimiento que es un sentido dinámico.

Entonces es la inteligencia misma, el hombre en cuanto ser inteligente, quien le da sentido a este lugar de conocimiento, quien le da sentido a esta actividad universitaria. Y entonces podríamos decir, propondría yo, que la universidad puede ser entendida como la institución de la inteligencia, o si se quiere mejor, la forma socialmente organizada de ella, el lugar social de la inteligencia. Pero hay que tener cuidado con lo que entendemos por esto de socialmente organizado. No significa que la inteligencia y, por consiguiente, la actividad que se realiza en la universidad, esta forma de institucionalización, sean algo rígido, estático, repetitivo; ya lo comentaba yo hace un momento. Pero tampoco significa el dejar a la sociedad como un ente autónomo que impone sus patrones, sus criterios, sus exigencias a este lugar que ella misma ha generado, ha formado y que ella misma, la sociedad, de alguna manera abarca, protege, cobija y para que quien sumisa, servilmente, la inteligencia atendería sus demandas. 
Aquí es en donde el papel viviente, activo, creador de la universidad en la sociedad va a tomar su fuerza primordial y en donde, como lo trataré también de señalar, la relación entre la inteligencia y la sociedad tiene que ser una relación de diálogo, pero de diálogo que comienza en el seno de la misma comunidad de profesores y de estudiantes. Esta forma socialmente organizada de la inteligencia significa, en su carácter de relación, de convivencia, una verdad dialogada. Una búsqueda y al mismo tiempo una posición, un alcance, un logro de la verdad en la comunicación, porque el diálogo es a la vez pensamiento y palabra.

Porque es en la sociedad, por la sociedad y para la sociedad, que los hombres se han reunido en esta búsqueda de la verdad; ese para la sociedad, repito, tiene que mantener siempre esta dinámica de revisión crítica que trataré de precisar en algún paso posterior. Las demandas sociales tienen que ser críticamente rectificadas, analizadas, discriminadas, dentro de la propia comunidad universitaria para que tengan, tanto ésta como la sociedad, mutuamente, la función que cada una de ellas ha de cumplir y la que recíprocamente esperan la una de la otra.

Ahora bien, regresemos al hecho que considerábamos al principio y ahondemos un poco más en él, hacia lo que está detrás de esa situación y que no es simplemente explicable por una relación de orden económico de la misma sociedad de consumo, por lo que la universidad aparece en la sociedad actual como esa tienda de departamentos. ¿Qué es lo que pasa? Encontramos lo que algún autor ha llamado la polémica de las dos culturas: expresión que otros impugnan en cuanto manera adecuada de expresar el problema, lo cual es motivo de que efectivamente haya polémica.

Esta pugna de saberes significa ante todo que en la actualidad el hombre, de manera especialmente marcada y clara, se encuentra ante una serie y orden muy diversos en cuanto a niveles de conocimientos. $Y$, por lo tanto, que el conocimiento no es algo uniforme, unidimensional, sino que requiere una diversidad también de métodos, lo que de alguna manera, pienso yo, ya los escolásticos querían expresar con la distinción de objetos, particularmente en las dos modalidades del objeto formal. 
Por una parte hay esta diversidad de conocimientos, pero por la otra, también, creo que el hecho que no podemos desconocer fuera de la polémica sobre una expresión concreta para designarlo, es que existe una incomunicación entre esos diversos conocimientos. Por eso la pugna de saberes, por eso la polémica de las dos culturas. Se da un encerrarse en la especialidad que es reconocid o de diferentes maneras por los autores que se ocupan de esto, pero en donde el asunto no queda simplemente en la ignorancia recíproca de los unos frente a los otros ("yo sé lo mío y lo tuyo no"); no es así, sino que el asunto va más allá y se plantea en esta línea de dos culturas y saberes que vendrían a ser finalmente, para decirlo con palabras que no nos dejen un poco en la oscuridad o en cierta a mbiguiedad, lo que se entiende por humanidades por un lado y lo que se entiende por campo científico o de la ciencia por el otro.

Más allá de esa ignorancia, existe también en nuestra cultura una hostilidad, hay unos que se sienten arriba, van con los signos de los tiempos, son los que en verdad hacen ciencia. $Y$ hay otros para los que el problema es sentirse siempre como en una situación de pérdida de credibilidad, en una situación en que se vive simplemente como un parásito tolerado, pero que finalmente en algún momento, cuando la sociedad llegue al pleno desarrollo de su éxito científico, podrá ser superada esa situación, eliminada esa superestructura.

Esto puede sonar un poco ridículo en la manera en que lo presento, pero no está muy lejos de lo que el maestro del positivismo nos dice en su ley de los tres estados o de lo que una interpretación materialista de la historia podría afirmar.

Esta situación de los de arriba y los de abajo, ¿cómo se proyecta en la educación? Es un problema desde luego más que de educación en un sentido restringido, de cosmovisión; y el problema no es de hoy, tiene tanta actualidad, por lo menos en las referencias que yo he podido localizar, como la actualidad que podemos encontrar en nuestro contemporáneo Aristóteles. Dice Aristóteles:

En la actualidad, está dividida la opinión en cuanto a las prácticas educativas, pues no todos están de acuerdo sobre lo que deben aprender los jóvenes, ya sea para la virtud, ya para la 
vida mejor, ni está dilucidado si conviene atender al cultivo de la inteligencia más bien que al carácter del alma..$^{9}$

Alguien que, ya no en este sentido irónico o quizás válido pero mucho más profundo de aquél que a primera vista suele dársele, sí es nuestro contemporáneo, este significativo escritor francés Eugenio Ionesco, nos dice después de haber asistido a una reunión de la UNESCO en Helsinki:

Me daba rabia escuchar esos delegados y sus delegaciones, con sus cuellos duros y sus corbatas, discutir acerca de puntos y comas, llenos de fatuidad y de una mediocridad inconsciente, sumergidos en el papel, fuera de toda verdad y de todo amor, queriendo administrar lo que no comprenden, el drama de la existencia, la tragedia humana, el problema de los fines últimos. Todo esto, angustia, fe, desesperanza, esperanza, estaba disecado, encerrado en cofres, puesto en las cajas de la cultura [en los supermercados de la cultura, diríamos nosotros poniendo al día a Gilson], falsas riquezas, falsas soluciones y sobre todo obstáculos a la verdad y a la vida. ${ }^{10}$

Sobre esta pugna, las palabras de Amorós tienen una fuerza muy sugestiva:

La literatura no sirve para nada concreto, para nada que se pueda medir odefinir con exactitud. Pertenece al ramo perfectamente inútil de las bellas artes, como un cuadro de Picasso o una sinfonía de Mahler. Para los sectores más inquietos, conviene hacer notar que la literatura no mejora la condición de los pueblos subdesarrollados ni elimina del mundo la opresión o la injusticia [...]

pero agrega el autor, y esto merece meditarse al menos de un modo inmediato y directo:

Y sin embargo, muchas de las cosas que son más importantes para mí, en mi vida concretá [y creo que la reflexión que yo proponía conceder al párrafo anterior, salva de cualquier repro-

9. Aristóteles, Politica, UNAM, México 1963, p. 236.

10 Apud José Ibáñez-Martín, Hacia una formación humanística, Herder, Madrid 1975, p. 69. 
产

che simplista de mentalidad pequeño burguesa, individualista, a lo que sigue diciendo] no se pueden medir, ni tienen directa traducción económica: una música, un amigo, el recuerdo de una tarde en que creí ser feliz. No estoy haciendo "literatura" sino mencionando cosas que son tan reales, como la cotización de bolsa o la tabla periódica de los elementos y que, para mi vida concreta, son mucho más importantes. ${ }^{11}$

Cuando hablamos de generalización, de unidad del saber, hablando al nivel administrativo, nos salimos del todo, nos salimos de la tienda. Nos colocamos en el verdadero lugar social de la inteligencia, en la universidad. Es preciso que haya ese principio arquitectónico; mientras no logremos esto, seguimos en esa situación de la rivalidad, de la pugna de saberes, de cultura y en la especialización, no en una visión integral. Y esta situación, dice Ibáñez-Martín en su libro especialmente sugestivo sobre la formación humanista, es gravemente dañosa "tanto para la sociedad como para la persona. En efecto, la incomunicación entre las culturas es una poderosa traba para la búsqueda creativa de nuevas soluciones a los problemas sociales". Pero además es una profunda fuente de frustraciones para las personas. ${ }^{12}$

Termino esta serie de referencias un poco más largas, con esta cita de nuestro querido Ortega, que llamo así porque me siento en deuda con él sobre todo por su definición de cultura que por bastante tiempo he tratado de entender y de asimilar para nuestra misma labor universitaria y académica en el Instituto. Ortega, en su estudio extraordinario sobre la misión de la universidad, cita al escritor chino Chuang Tse, quien le hace decir al dios del mar del Norte:

¿Cómo podré hablar del mar con la rana si no ha salido de su charca? ¿Cómo podré hablar del hielo con el pájaro de estío si está retenido en su estación? ¿Cómo podré hablar con el sabio acerca de la Vida, si es prisionero de su doctrina? ${ }^{13}$

". Apud ibid., p. 13.

12 Ibid.

13. José Ortega y Gasset, Misión de la universidad, Revista de Occidente, Madrid $1968^{5}$, p. 31. 
Yo quisiera aclarar que, para quienes en serio se interesan por la situación del hombre y de la sociedad de nuestra época, la ciencia y la técnica son indiscutiblemente y en forma primordial bienes extraordinarios, grandes valores positivos, bienes indudables que la sociedad pone a nuestro alcance. Quizás más bien y con un poco de sentido común y en forma bastante sensata, lo que algunos reclamemos a la ciencia y a la técnica, no es que hayan ido demasiado lejos, sino que todavía van muy despacio, que todavía han hecho demasiado poco.

El problema es otro, el problema está donde el hombre está en peligro, los reparos tienen su origen en donde la ciencia y la técnica empiezan a imponer sus propias leyes en una forma que cada vez más la situación del hombre contemporáneo aparece bajo el absolutismo de estos dominios, cuando expresiones como "sociedad científica" o "sociedad tecnológica" tienen una carga axiológica en el sentido de determinar los valores supremos.

En estas condiciones, los que estarían en la función de los humanistas tienen un papel muy incómodo, el papel de juez. Y, ciertamente, el árbitro a veces puede tener ciertos sesgos en sus juicios, y a veces puede ceder al soborno o en cualquier otra forma atender a sus intereses particulares. Pero no por eso podemos prescindir de los árbitros, son indispensables.

Este sentido de unidad, este sentido de estructura y de principio arquitectónico es lo que necesitan los saberes y el conocimiento de nuestros días. Esta vida universitaria, o que quiere llamarse así, mejor dicho, que quiere ser y aunque así se llame, quizás sin serlo, está presentando esta necesidad de hacer una referencia a la vida del conocimiento y de la inteligencia, una referencia a los valores que corresponden al auténtico ser del hombre y de toda la realidad. Para lograrlo, esta vida requiere de quién tenga ese amargo, ese incómodo, ese a veces excedido o mal ejercido papel de juez, de árbitro, de crítico. Pero, de cualquier manera, es indispensable su función. Y yo creo que aquí es en donde empiezan los malentendidos y regresamos a los de arriba y a los de abajo. Es el problema de perder de vista el que alguien tiene que decir precisamente del todo como tal y de las partes en cuanto tales, y que esa es su función. 
Mientras esto no se entienda, todas las actuaciones o todas las intervenciones de quien en un momento dado, quizás con un cierto estilo pedagógico, pone más el acento en lo negativo que en lo positivo, porque lo negativo es lo que parece más amenazador, más inminente, entonces todas sus intervenciones serán objeto de ataques e incomprensiones y las protestas e incomodidades a causa de su intervención no cesarán nunca.

Hay un título de las semanas sociales de Francia que a mí siempre me ha parecido muy sugestivo: ¿qué economía, para qué sociedad? El problema no es que la economía sea valiosa y necesaria; indudablemente el problema es otro (¿qué economía y para qué sociedad?) ya que ese es el problema del hombre y el problema de los fines. Y esto nos lleva al otro elemento, al otro término de nuestra exposición, que a lo mejor ya hasta se nos olvidó o se les olvidó a ustedes; a mí sí, ya se me había olvidado: la filosofía.

El mismo autor que mencioné al empezar a hablar de la universidad, Etienne Gilson, tiene (y estoy aquí con esa sabiduría de librería, simplista, de títulos, pero es interesante a veces analizar ya el mero título, lo que éste puede indicar) un libro que ciertamente puede resultar decepcionante para quien con un ánimo picaresco pero también con una fuerte dosis de ignorancia vaya a su lectura, el libro se llama Las tribulaciones de Sophía. Esto nos sugiere cuál es la situación en que se encuentra la filosofía y, por tanto, la de los que la siguen. Ciertamente esta "buena dama", de cuyas tribulaciones nos quiere hablar Gilson, siempre ha tenido atribulados a los caballeros que a ella se dedican.

La filosofía, desde sus orígenes, tal como encontramos que surge en la cultura occidental y en concreto en Grecia, se presenta como el ámbito por excelencia de la racionalidad. Y, ¿por qué digo el ámbito por excelencia? Porque precisamente en la filosofía el hombre tiene la pretensión o el intento de habérselas con el todo, con la realidad en su conjunto, con la realidad a secas, la filosofía es en donde su mismo quehacer, en donde su mismo instrumento o sus recursos para habérselas con el todo, entra dentro de su propia revisión y discusión.

Podríamos esperar que al hacer las consideraciones en las que revisemos o veamos qué es lo que la filosofía contiene, nos 
fuéramos valiendo de definiciones, pero esto sería, además de bastante largo, algo que nos llevaría al tema mismo del quehacer filosófico, pero el objeto nuestro ahora es bastante más limitado. Con todo, para quien entiende esto, no debe ser algo extraño, sino más bien la confirmación de que el asunto anda por buen camino, el encontrar que existen muchas y divergentes definiciones acerca de la filosofía. Nosotros vamos por ahora a quedarnos simplemente con el nombre.

Si la etimología de filosofía nos indica algo importante es que está más en el quehacer y en la búsqueda que en la posesión. Su etimología, como lo sabemos, es amor a la sabiduría, y si bien el concepto de sabiduría requeriría ser un poquito más precisado y analizado, lo que podemos destacar sobre todo para entender esto en relación a lo que empecé diciendo de esa racionalidad y de esa apertura totalizadora, de esa intención totalizadora mejor, es que la sabiduría tal como inicialmente y universalmente ha sido entendida, tiene un carácter ante todo y sobre todo práctico. Significa el saber vivir. Aunque ya más técnica y propiamente en el campo de la filosofía occidental sería esa manera de lograr la comprensión de la realidad de que parte, que se apoya en los primeros principios, en las causas últimas, lo cual ya no tiene, al menos en el sentido más técnico, un carácter propiamente práctico sino estricta y fundamentalmente especulativo, teórico. No obstante esto está mucho más hondamente ligada al saber vivir que lo que suelen creer los hombres, particularmente los "hombres prácticos" de hoy día.

Este amor a la sabiduría, este ejercicio y esta búsqueda, requieren de un esfuerzo, de un trabajo ascético, de una lucha. Y si bien yo decía hace un momento que lo principal está en la misma actividad, en este buscar saber, más que en la posesión, hay que tener cuidad o en cómo entendemos esta doble situación frente a la verdad y frente a la sabiduría dentro de la filosofía. Y para ello podemos valernos de la distinción entre filosofar y filosofía. En realidad, si hablamos de filosofía, lo primero que podríamos preguntar es, ¿cuálfilosofía? Filosofías hay muchas, hay que ponerle el plural a este término. Pero de cualquier manera, si hacemos esta distinción muy radical entre filosofar y filosofía nos excedemos y podemos poner el acento en la búsqueda hasta olvidarnos totalmente de la posesión. Pienso yo 
que esto incluye una trampa, porque finalmente el método y la acción misma del filosofar como camino, la búsqueda, no pueden simplemente mantenerse en la negación del término del camino, quedarse en la aporía, porque esto sería la negación misma de la filosofía: el escepticismo; la filosofía sería la búsqueda que no conduce a nada, la búsqueda de nada. Claro está que el escepticismo también se mantiene como postura filosófica pero habría que ver con qué malabarismos, aunque quizás esto suene demasiado simplista.

Creo que la distinción más sugerente entre filosofar y filosofía podría mos interpretarla mejor ayudándonos de aquella distinción de Nicolai Hartmann entre filosofías sistemáticas y filosofías problemáticas. Las sistemáticas son las que se sienten en posesión definitiva $\mathrm{y}$, digámoslo así, omnicomprensiva, pretenden haber llegado a comprenderlo todo. Las filosofías problemáticas, en cambio, están siempre sujetas y dispuestas a la crítica y a la autocrítica, siempre en la conciencia y en la claridad de que en los contenidos logrados hay (si no en una forma absoluta y radical, porque entonces seguiríamos en la aporía, en el sin-camino) una cierta falta, alguna ausencia, un cierto carácter provisorio, un cierto carácter de provisional. Y si la filosofía es, en esta pretensión de totalidad, esta búsqueda de lo fundamental, de la cosmovisión, de esta idea del hombre, del mundo y de la vida, es también esta posesión o este estar en relación al mundo con una cierta idea de él y de sí mismo.

Todos los hombres tienen una presencia de hecho, todo hombre de alguna manera tiene una manera de ver el mundo y la vida, todo hombre en este sentido, por su misma experiencia, de una manera espontánea, recibiendo desde luego la influencia del medio (y habría que ver en esto toda una serie de ruedas de molino con que tiene que tragar), tiene una manera de pensar que llega a pensar propia.

Hay por otro lado sujetos raros, raros porque no son comunes, que por vocación y por profesión llegan o están en esa búsqueda, en ese ejercicio hacia una posesión activa y personal del saber filosófico, de la verdad filosófica. En este plano es en donde estamos ya encontrando el nexo entre filosofía y universidad. En la medida en que esa creencia que todo hombre tiene del mundo, de la realidad, este sistema de creencias del que 
habla Ortega, simplemente lo deja sin más como una parte, desde luego en la que se apoya, de su equipaje, pero sin más, esta situación acrítica, esta situación meramente de vivir con ciertas ideas, pero no vivir - consciente, temáticamente mejor- de esas ideas, ni revisar qué tanto vale la pena vivir conforme a ellas, esta situación sería la de la filosofía como conciencia puramente "a-temática".

La filosofía, en cuanto les da ser a esos sujetos raros, es una posesión activa y personal, que podemos llamar propiamente actividad y tarea de los filósofos.

Alguien ha dicho que la almohada del hombre de ciencia es la duda, lo cual en un orden metodológico es perfectamente válido y especialmente necesario para el filósofo, sin que con esto esté yo manifestando un credo cartesiano que no profeso. Se trata simplemente de procurar la liga necesaria entre filosofar y filosofía al modo de lo que Hartmann llama filosofías problemáticas.

¿Dónde está entonces el grado, la densidad, la liga entre universidad y filosofía? ¿Qué tanto universidad y filosofía soportan esta ilación y le dan verdaderamente sentido y desde dónde o en qué perspectiva?

Si decía yo hace un rato que la universidad es la forma en que la sociedad misma vive la actividad intelectual, es la forma socialmente organizada de la inteligencia, y por otro lado la filosofía y el filosofar están en esta inseparable relación y complementación, son un ejercicio en que todo se somete a revisión y se autofundamenta ("¿por qué hay algo en vez de nada?", dice Heidegger), se somete a revisión y se autofundamenta desde la misma capacidad de comprender y explicar las cosas o sea, la inteligencia, creo que está claro cuál es el grado de nexo y de unión que hay entre universidad y filosofía: el lugar social de la inteligencia no puede ser tal sin serlo a la vez de la filosofía, más aún, lo es plenamente a la luz de ésta.

Sin embargo, no se nos olvide que hay un hecho por el que empecé, la situación de la universidad, la situación de la pugna de saberes, una crisis que no necesariamente es como parece que algunos autores piensan que es o tiene que serlo en el caso de la filosofía, algo permanente. Lo acabo yo de decir con otras palabras hablando de esta incómoda almohada del filósofo; si 
de alguna manera las crisis son algo permanente, hay también ( $y$ esto en serio en la vida solamente pasa una vez), crisis que son estertores. Cuando los estertores comienzan ya no hay nada que hacer, ya no hay esperanza de someter al paciente a una operación porque si sus defensas, si sus recursos fallan, desde fuera no se puede hacer nada con él.

La crisis de la universidad y la crisis de la filosofía, en la medida en que constituyen la crisis de la inteligencia en nuestros días, creo que son algo que merece un cuidado especialmente insistente, sin demora y a la vez lleno de precauciones. Y esta crisis de la inteligencia, simplemente enumero algunos de sus ángulos, algunos de sus rasgos, de sus ámbitos, va en esa sorprendente mezcla de una enorme confianza del hombre en llegar a saberlo todo y poderlo todo; confianza que quizás el hombre que más piense en nuestros días cada vez tiene ya menos, pero que todavía como mentalidad, como cosmovisión dominante existe en gran parte de los seres humanos, esta especie de progreso infalible y plenamente exitoso que viene de las ideas del siglo XVIII; pero esto va poco a poco impregnándose sin desaparecer, de la quiebra de esta misma esperanza, la tremenda desconfianza y la sensación de la impotencia mayúscula. No en vano, en nuestra época misma, han surgido diferentes manifestaciones sumamente expresivas de esta fuerza de la irracionalidad. El sentido de la palabra se ha perdido, no digamos ya por la mentira institucionalizada, peor todavía y más grave cuando es dentro de la misma institución de la inteligencia que es la universidad, en donde ya no se cree, en donde cada vez más el ser humano exagera este sentido de la duda.

Esto se percibe porque hoy el hombre cada vez vive más en una situación de desconfianza, de sensación de que va a ser sorprendido, de que el hombre que con el que se cruza, el hombre con el que cambia palabras, tiene inmediatamente la intención de darle un zarpazo.

Por otro lado, esta crisis de la inteligencia también se advierte cuando encontramos la común confusión entre verdad y sinceridad. Se advierte cuando se pierde el sentido del misterio del hombre porque simplemente se postula que hay que encontrar "un más allá de la libertad y la dignidad". Y todo esto 
conduce a que se confunda tan comúnmente lo importante con lo urgente, porque no hay sentido, no hay jerarquía, no hay brújula, no hay rumbo.

En este aspecto, yo veo una fuente especialmente preocupante de esta crisis de la inteligencia en la unidimensionalidad, que es como el tema intelectual de nuestra manera de pensar, "el postulado fundamental (según dice García Morente en su discurso sobre la universidad) del pensamiento moderno: la exclusión de todo conocimiento no científico". ${ }^{14}$ No queda entonces sino una pluralidad de saberes, pero una imposibilidad de saber. ¿Qué es saber? La pregunta de Kant, la pregunta por el sentido de la inteligencia teórica iría en primer orden y, ante todo, ¿qué podemos saber? Parece que el propio Kant de alguna manera fue abriendo terreno para cavar su tumba, la de la inteligencia.

Como que se ha hecho una condena de la inteligencia sin audiencia. No se le ha oído, porque la inteligencia se considera totalmente desacreditada. Se ha pensado, se cree ya que no tiene ninguna dignidad y por lo tanto que es totalmente incapaz para hablar, para tener derecho a hablar, para teneralgún derecho, y desde luego primordialmente para poder hablar de algo con sentido.

Los mismos intelectuales, y aquí la generalización sería totalmente injusta, pero sí buena parte de ellos o de los que así son llamados, tienen una actitud vergonzante, se rehusan a hablar y a tomar en serio realidades como la dignidad y la trascendencia, las cuales habrían de ser la condición de validez de su ejercicio.

Para terminar, y de manera muy breve y meramente enunciativa, apuntaré algo de lo que al comienzo indiqué como perspectivas resultantes dé la revisión que hemos hecho; se trata de algunos aspectos principales de la función de la filosofía dentro de la universidad en la doble dimensión que está presente en ella como investigación y docencia.

Por una parte debe llevarse al cabo la enseñanza de la filosofía en el sentido que aquí queda entendida. Igualmente debe cumplirse una tarea epistemológica en cuanto compete a la

14 Op. cit., p. 34. 
filosofía una labor crítica y el tratamiento de las condiciones de posibilidad de la integración del saber.

En cuanto la universidad debe contribuir significativamente a la formación integral de la perșona y al genuino desarrollo de la sociedad en íntima relación con esa formación, la filosofía debe a la vez participar como enseñanza en esa formación y como investigación de los criterios para establecer el significado y sentido de lo que por tal formación y tal desarrollo se entiende.

Por el carácter eminentemente teorético y de búsqueda de la filosofía, la universidad contará con las condiciones que le permitan cumplir con su función social como realizadora de cultura, estando a la vez inmersa en la sociedad, con una plena pertenencia y a la vez dentro de la más plena libertad.

Hay que defender la inteligencia si queremos salvar la universidad, si no queremos privar al hombre y a la sociedad de una óptima, más aún necesaria condición para salvaguardar su dignidad y lograr su desarrollo integral. Esta tarea pertenece, en forma por demás propia, en primer término a la filosofía. 